\title{
A modelling study of eddy-splitting by an island/seamount
}

\author{
Shengmu Yang ${ }^{1,2}$, Jiuxing Xing ${ }^{1}$, Daoyi Chen ${ }^{1,2}$, and Shengli Chen ${ }^{1}$ \\ ${ }^{1}$ Shenzhen Key Laboratory for Coastal Ocean Dynamic and Environment, Graduate School at Shenzhen, \\ Tsinghua University, Shenzhen, 518055, China \\ ${ }^{2}$ School of Environmental Science and Engineering, Tsinghua University, Beijing, 100084, China \\ Correspondence to: Shengmu Yang (ycm15@mails.tsinghua.edu.cn) and Daoyi Chen (chen.daoyi@sz.tsinghua.edu.cn)
}

Received: 10 November 2016 - Discussion started: 5 December 2016

Revised: 17 September 2017 - Accepted: 18 September 2017 - Published: 25 October 2017

\begin{abstract}
A mesoscale eddy's trajectory and its interaction with topography under the planetary $\beta$ and nonlinear effects in the South China Sea are examined using the MIT General Circulation Model (MITgcm). Warm eddies propagate to the southwest while cold eddies propagate to the northwest. The propagation speed of both warm and cold eddies is about $2.4 \mathrm{~km} \mathrm{day}^{-1}$ in the model. The eddy trajectory and its structure are affected by an island or a seamount, in particular, under certain conditions, the eddy may split during the interaction with an island/seamount. We focus this research on two parameters $R$ and $S$ (where $R$ and $S$ are two dimensionless parameters of the island size and submergence depth; $R$ is the ratio of the island radius to the eddy radius, and $S$ is the ratio of the seamount submergence depth to the eddy vertical length). The results of sensitivity experiments with varying island or seamount geometry indicate that the eddy would split in the qualitative range of $1 / 4<R<2$ and $S<1 / 5$. The scale of the secondary eddy split-off decreases as the island diameter or the seamount submergence depth increases. In the splitting process, besides the off-spring eddy, there are also some filaments or eddies with opposite vorticity appearing around the eddy. Eddy-splitting, therefore, is an important way to transform energy from the mesoscale to sub-mesoscale in the ocean.
\end{abstract}

\section{Introduction}

Eddies are common in oceans, both at surface and deep layers, including mesoscale eddies (scale of $100 \mathrm{~km}$ ) and submesoscale eddies (scale of $10 \mathrm{~km}$ ) (Itoh et al., 2011; Oey, 2008; Olson et al., 2007). Eddies have gained much attention since they are an important form of material and energy transfer in the ocean (Zhang et al., 2011, 2013, 2014; Kersalé et al., 2013; Waite et al., 2007; Jacob et al., 2002; Wang et al., 2005). Although isolated eddies in open oceans are affected by different factors, many of them have similar kinematic characteristics in general. As many researchers have pointed out, an isolated warm eddy in open oceans moves southwestwards or moves northwards along the western boundary in the northern hemisphere under the planetary $\beta$ and nonlinear effects (Chang et al., 2012; Wei and Wang, 2009; Nof, 1981; Itoh et al., 2011; Itoh and Sugimoto, 2001; Nan et al., 2011; Cushman-Roisin et al., 1990; Korotaev and Fedotov, 1994). Sutyrin et al. (2003) came to the conclusions that $\beta$-induced propagation of surface anticyclones drive lower-layer eddies, which add a significant southerly component to surface eddy propagation.

The eddy propagation in the ocean is directly affected by topography. The eddy trajectory and structure can be changed due to the interaction with a continental slope, an island or a seamount. The interaction between a warm eddy and a continental shelf slope has been investigated by many researchers based on satellite observations, laboratory and numerical model experiments (Hyun and Hogan, 2008; Rennie et al., 2007; Sutyrin and Grimshaw, 2010; Wei and Wang, 2009; Itoh and Sugimoto, 2001; Smith and O'Brien, 1983). A continental slope is often treated as a wall in the numerical model studies. Previous studies indicate that the eddy-wall collision can cause the eddy to leak water along the wall and generates along-wall jets which can be related to nonlinear Kelvin waves (Nof, 1988; Shi and Nof, 1994; Reznik and Sutyrin, 2005). When a patch of fast moving water catches up with a slower one, an eddy could be generated near the nose of the along-wall jet (Stern, 1986, 2010). Besides the jets and eddies, during the evolution of an isolated eddy near a wall, 
nonlinear Kelvin waves can be excited due to the geostrophic adjustment, which can trap and transform water along the wall (Umatani and Yamagata, 1987; Dorofeyev and Larichev, 1992). In contrast to the case with a continental slope, when eddies encounter an island or seamount, the eddy could split into two eddies because of the erosion by the isolated topography (Herbette et al., 2003, 2005; Simmons and Nof, 2002; Dewar, 2002; Luo and Liu, 2006; Cenedese, 2002).

Simmons and Nof (2000) obtained the essential conditions for a barotropic eddy splitting by using a wall moving into the eddy: even for infinitesimal splitting, which arises from weak collisions, the wall length must be at least a radius of the eddy. Drijfhout (2003) discussed the anticyclonic eddy splitting mechanism which is that anticyclones cannot split by barotropic processes alone, and baroclinic instability is a necessary ingredient for splitting to occur. Using an isopycnal ocean circulation model, Herbette et al. (2003) analysed the behaviour of a surface-intensified anticyclonic eddy encountering an isolated seamount, and the erosion often results in a subdivision of the eddy. Wang and Dewar (2003) studied the meddy-seamount interaction. The initial meddy splits into two meddies in their experiments, but meddies are able to survive as coherent vortices because of strong potential vorticity anomalies (PVAs). Numerical estimates of the transformed eddy structure indicate that topographic interactions provide powerful mechanisms for the baroclinic eddy evolution (Sutyrin et al., 2011).

There are plenty of mesoscale and sub-mesoscale eddies existing in the South China Sea (SCS), and most of them propagate to the southwest (Chang et al., 2012; Nan et al., 2011). In particular, mesoscale eddies occur frequently in the northern SCS (Hwang and Chen, 2000; Chang et al., 2012; Zhang et al., 2013; Nan et al., 2011; Wang et al., 2003, 2005), and the number of cold eddies is similar to that of warm eddies. Therefore, it is of importance to find out the difference between the cold and warm eddies.

Furthermore, the SCS is populated with numerous islands and seamounts. Therefore, most eddies are affected by the topography variation in their movement. The change of eddy structure over topography has an important influence on its dynamics, while it is an important means of energy transfer among different scales and affects the coastal ocean environment (Kersalé et al., 2013; Drijfhout, 2003; Dunphy and Lamb, 2014). Chang et al. (2012) found from satellite observations that an anticyclonic eddy (warm eddy) with a diameter of $120 \mathrm{~km}$ was split by the Dongsha atoll situated on the slope in the northern SCS. Because of difficulties in catching the entire process of eddy splitting by both satellite observations and in situ measurements, there are a few cases of eddy-island interactions found by satellite images so far. Particularly, the phenomenon of eddy-splitting reported in Dongsha in the SCS lacks sufficient measurement data to systematically describe the process of splitting (Chang et al., 2012). In addition, eddies may split during interaction with a curved continental slope. Kersalé et al. (2013) investigated a coastal anticyclonic eddy in the western part of the Gulf of Lion in the northwestern Mediterranean Sea, where eddies split in a similar pattern as in the case of the Dongsha atoll. This provides a wider application prospect for any eddy-splitting role in the interaction with topography. However, it is not clear whether an eddy can always be split by an island/seamount and how the scale of the isolated topography influences the eddy-splitting. Recently, Li et al. (2016) used the Genealogical Evolution Model (GEM) to track the dynamic evolution of mesoscale eddies in the ocean. They can distinguish between different dynamic processes including merging and splitting, but the special processes and characteristics of eddy splitting by an island have not been elucidated completely.

In this study, we constructed an idealized eddy in a numerical model according to the features of the observed eddies in the SCS to examine its kinematic characteristics and test eddy splitting processes using numerical simulations. Moreover, inspired by the eddy splitting near the Dongsha island in the SCS, we vary the island size and seamount submergence depth to investigate the influence of the island on the eddy, and then to analyse the effect of the island and the seamount on the mesoscale eddy evolution (weakening and destruction) as the eddy approaches the obstacles.

This paper is organized as follows: Sect. 2 describes the eddy structure used in the model and the method of eddy identification. Section 3 introduces the model. The model results, including a comparison of eddy trajectories between the warm eddy and cool eddy, and the effect of an island and seamount on eddy deformation will be presented in Sect. 4 . A summary and discussion is given in Sect. 5.

\section{An idealized mesoscale eddy}

\subsection{The eddy structure}

An idealized mesoscale eddy is initialized with an axisymmetric Gaussian-type profile based on long term moored observations (Zhang et al., 2013), Argo float data and the merged data products of satellite altimeters (Chen et al., 2010). Temperature profiles from observations are fitted into an equation of

$T(z)=T_{\mathrm{b}}(z)+a_{z} e^{-\frac{x^{2}+y^{2}}{2 L^{2}}}$,

where $T_{\mathrm{b}}(z)$ is background temperature; $a_{z}$ is a function parameter varying with depth $(z)$ and $L$ is constant $1.5 \times 10^{4} \mathrm{~m}$; $x, y$ and $z$ are position coordinates.

The eddy's initial velocity is calculated using the thermal wind balance with zero velocity at the ocean bottom. The density distribution is obtained from a state equation according to Jacket and Mcdougall (1995). Figure 1 shows the temperature and azimuthal velocity distribution on the cross section through the eddy centre. The initial eddy is $60 \mathrm{~km}$ in diameter and $500 \mathrm{~m}$ in depth with a total water depth of $2000 \mathrm{~m}$. 

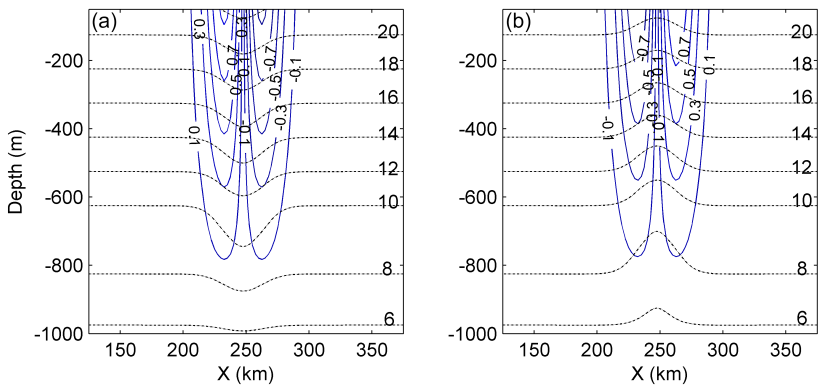

Figure 1. Initial velocity $\left(\mathrm{m} \mathrm{s}^{-1}\right)$ and temperature $\left({ }^{\circ} \mathrm{C}\right)$ profiles of the model warm eddy (a) and cold eddy (b).

The maximum surface velocity is about $0.9 \mathrm{~m} \mathrm{~s}^{-1}$, and the maximum surface elevation is $0.5 \mathrm{~m}$.

\subsection{Eddy identification and definition of the eddy boundary}

There are different methods to identify an eddy and here we use the Okubo-Weiss method (Okubo, 1970; Weiss, 1991) to identify the eddy that we constructed in the model and define the boundary of the eddy. The Okubo-Weiss parameter $W$ is given by

$W=s_{\mathrm{n}}^{2}+s_{\mathrm{s}}^{2}-\omega^{2}$,

$\omega=\frac{\partial v}{\partial x}-\frac{\partial u}{\partial y}, s_{\mathrm{n}}=\frac{\partial u}{\partial x}-\frac{\partial v}{\partial y}, s_{\mathrm{s}}=\frac{\partial v}{\partial x}+\frac{\partial u}{\partial y}$,

where $\omega$ is the vertical component of relative vorticity; $s_{\mathrm{n}}$ and $s_{\mathrm{S}}$ represent the strain and shear deformation, respectively; and $u$ and $v$ are eastward and northward velocities, respectively.

Because the velocity field within an eddy is dominated by its rotation, ocean eddies are generally characterized by negative values of $W$. In this study, we use $W<-0.2 \sigma_{\mathrm{w}}$ to define the core region of the eddy, where $\sigma_{\mathrm{w}}$ is the standard deviation of $W$ in the study region. This way to identify an eddy has a tendency towards excess of eddy detection (Doglioli et al., 2007), so we combine the PVA distribution, velocity field and temperature anomaly to determine the main eddy that we focus on, and ignore the smaller circulations due to the eddytopography interaction.

\section{Numerical model and initialization}

The MITgcm (MIT General Circulation Model; Adcroft et al., 2011) is used in this study. Its non-hydrostatic formulation enables us to simulate fluid phenomena over a wide range of scales. However, we only use the hydrostatic form of the model as we expect that the non-hydrostatic dynamics play minor roles in our problem (to capture the non-hydrostatic dynamics we would have to use a much finer resolution than used here). The model domain is
$500 \mathrm{~km} \times 450 \mathrm{~km}$, and the depth of the ocean used in the model is $2000 \mathrm{~m}$. The horizontal resolution is $2.5 \mathrm{~km}$; in the vertical, 28 levels are used with $50 \mathrm{~m}$ resolution in the upper $1000 \mathrm{~m}$ and the resolution gradually coarsens in the lower $1000 \mathrm{~m}$. The Coriolis parameter $f=9 \times 10^{-5} \mathrm{~s}^{-1}$ and the planetary parameter $\beta=2 \times 10^{-11} \mathrm{~m}^{-1} \mathrm{~s}^{-1}$ (here the main reason to use $\beta$ plane rather than $f$ plane is the $\beta$ effect being the main force for the movement of an eddy, see Sect. 4). The model boundaries are all open, and the Orlanski radiation condition is used. In the horizontal, we use Smagorinsky viscosity with a parameter of 0.2 . In the vertical, the eddy viscosity is $5.0 \times 10^{-4} \mathrm{~m}^{2} \mathrm{~s}^{-1}$. For the temperature equation, the vertical eddy diffusivity is $10^{-4} \mathrm{~m}^{2} \mathrm{~s}^{-1}$ and horizontal eddy diffusivity is set to zero.

In the model, both the warm eddy and the cold eddy are initialized with an axisymmetric Gaussian-type profile described in Sect. 2. The temperature decreases with the depth in the upper $1000 \mathrm{~m}$ and is set to a constant value of $4{ }^{\circ} \mathrm{C}$ below $1000 \mathrm{~m}$. A constant salinity of $35 \mathrm{psu}$ is used, which does not affect the model results.

For the model with flat topography, the eddy is located at the centre of the model domain to test the difference between warm- and cold-eddy trajectories. In the cases studying the interaction between an eddy and an island/seamount, the island/seamount with different sizes/depths is located in the central path of the eddy, and all islands and seamounts are cylinder shaped. We run the model from the initial state of rest for 50 days in order to compare different effects of obstacles on eddies.

\section{Results}

Our main attention is on eddy-splitting due to the interaction between eddies and obstacles, and a series of experiments based on the idealized eddy structure in the SCS have been carried out (Table 1). The eddy diameter is $60 \mathrm{~km}$, and the initial location of the eddy centre is $x=250 \mathrm{~km}, y=225 \mathrm{~km}$.

We first examine the eddy trajectories and its characteristics without any island/seamount. Then we focus on the interaction between the eddy and the island/seamount, and the sensitivity of eddy-splitting to the island size and seamount depth.

\subsection{The trajectories of warm and cold eddies}

In our first set of numerical experiments, an eddy (warm or cold $)$ is located at the centre $(x=250 \mathrm{~km}, y=225 \mathrm{~km})$ of the domain with open boundaries and a flat bottom (Fig. 2). When the eddy is a warm eddy (anticyclonic eddy in the northern hemisphere), it moves towards the southwest direction in a flat bottom ocean. At the beginning of the model integration, the eddy will adjust itself to a dynamic balance. As a result, the speed of the eddy movement is relatively small. After the model reaches its balance, the speed of the eddy 
Table 1. List of different topography used in the experiments.

\begin{tabular}{lllrll}
\hline Case & Type & Diameter & $\begin{array}{r}\text { Submerge } \\
\text { depth }(\mathrm{m})\end{array}$ & Centre location & Outcome \\
\hline 1 & flat & - & - & - & \\
2 & island & $10 \mathrm{~km}$ & 0 & $(213,176 \mathrm{~km})$ & no splitting \\
3 & island & $15 \mathrm{~km}$ & 0 & $(211,174 \mathrm{~km})$ & split \\
4 & island & $25 \mathrm{~km}$ & 0 & $(207,170 \mathrm{~km})$ & split \\
5 & island & $60 \mathrm{~km}$ & 0 & $(195,158 \mathrm{~km})$ & split \\
6 & island & $90 \mathrm{~km}$ & 0 & $(184,147 \mathrm{~km})$ & weak splitting \\
7 & island & $120 \mathrm{~km}$ & 0 & $(173,136 \mathrm{~km})$ & weak splitting \\
8 & island & $150 \mathrm{~km}$ & 0 & $(162,125 \mathrm{~km})$ & weak splitting \\
9 & island & $300 \mathrm{~km}$ & 0 & $(109,72 \mathrm{~km})$ & filament \\
10 & island & infinite & 0 & - & filament \\
11 & seamount & $15 \mathrm{~km}$ & 50 & $(211,174 \mathrm{~km})$ & no splitting \\
12 & seamount & $15 \mathrm{~km}$ & 80 & $(211,174 \mathrm{~km})$ & no splitting \\
13 & seamount & $15 \mathrm{~km}$ & 100 & $(211,174 \mathrm{~km})$ & no splitting \\
14 & seamount & $60 \mathrm{~km}$ & 50 & $(195,158 \mathrm{~km})$ & split \\
15 & seamount & $60 \mathrm{~km}$ & 80 & $(195,158 \mathrm{~km})$ & split \\
16 & seamount & $60 \mathrm{~km}$ & 100 & $(195,158 \mathrm{~km})$ & weak splitting \\
17 & seamount & $60 \mathrm{~km}$ & 200 & $(195,158 \mathrm{~km})$ & filament \\
18 & seamount & $60 \mathrm{~km}$ & 500 & $(195,158 \mathrm{~km})$ & no splitting \\
19 & seamount & $60 \mathrm{~km}$ & 1000 & $(195,158 \mathrm{~km})$ & no splitting \\
20 & seamount & $90 \mathrm{~km}$ & 50 & $(184,147 \mathrm{~km})$ & split \\
21 & seamount & $120 \mathrm{~km}$ & 100 & $(173,136 \mathrm{~km})$ & no splitting \\
22 & seamount & $120 \mathrm{~km}$ & 150 & $(173,136 \mathrm{~km})$ & no splitting \\
23 & seamount & $150 \mathrm{~km}$ & 100 & $(162,125 \mathrm{~km})$ & no splitting \\
\hline & & & & & \\
\hline
\end{tabular}

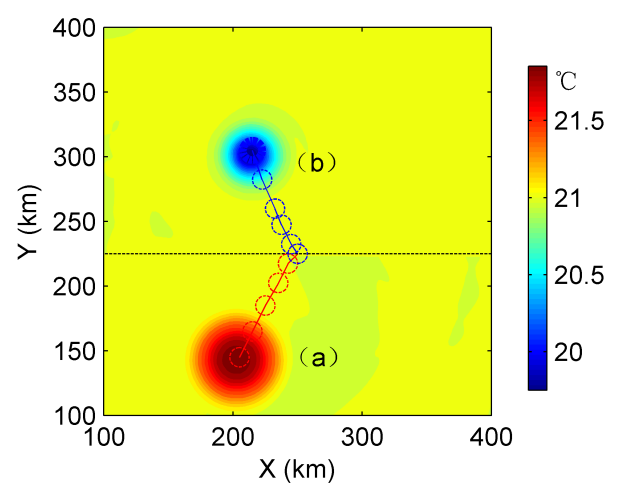

Figure 2. Eddy trajectory over a flat bottom ocean: (a) warm eddy; (b) cold eddy for 50 days. The temperature field shown in colour is a snapshot of the eddy at $t=50$ days at $100 \mathrm{~m}$ depth. The trajectory of the eddy centre is depicted by circles every 10 days.

increases, to a constant value of $2.4 \mathrm{~km} \mathrm{day}^{-1}$ after 40 days. The speed of the warm eddy in the model is similar to that of the study of (Wei and Wang, 2009). The eddy propagation speed is influenced by the eddy size and the $\beta$ effect, which is a function of the local latitude. Therefore at a different latitude, the eddy has different speed. Figure 3 shows that the average speed over 50 days of the warm eddy is $1.75 \mathrm{~km} \mathrm{day}^{-1}$, which is smaller than the eddy speed in the natural conditions

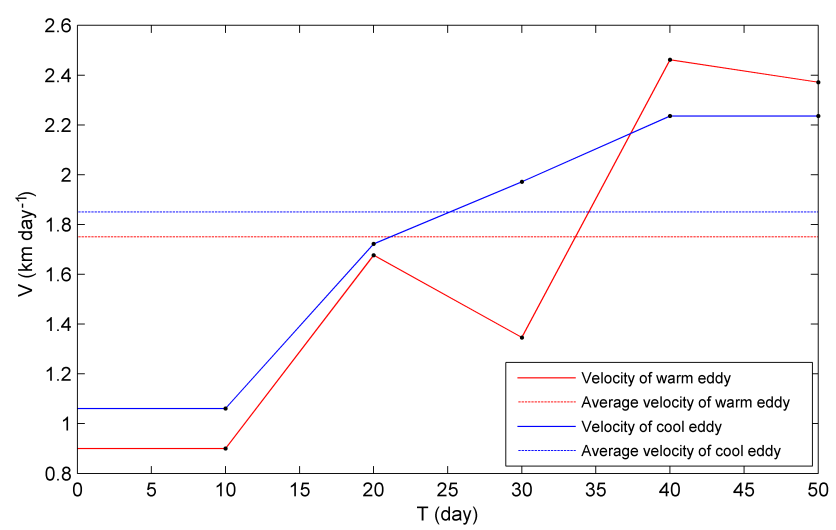

Figure 3. The speed of eddies over a flat bottom ocean. Solid lines: time series of speed; dashed lines: the speed averaged over 50 days.

in the SCS region because of the adjustment in the early stage of the model run.

With a cold eddy (cyclonic eddy in the northern hemisphere) in the same situation, the movement direction is northwest under $\beta$ and nonlinear effects. The speed increases from the beginning of the model integration which is the same as for the warm eddy. The speed reaches a constant value of $2.3 \mathrm{~km} \mathrm{day}^{-1}$ after 40 days. From the trajectory and speed variation during the eddy movement, we can see that the warm and cool eddy have similar kinematic characteris- 

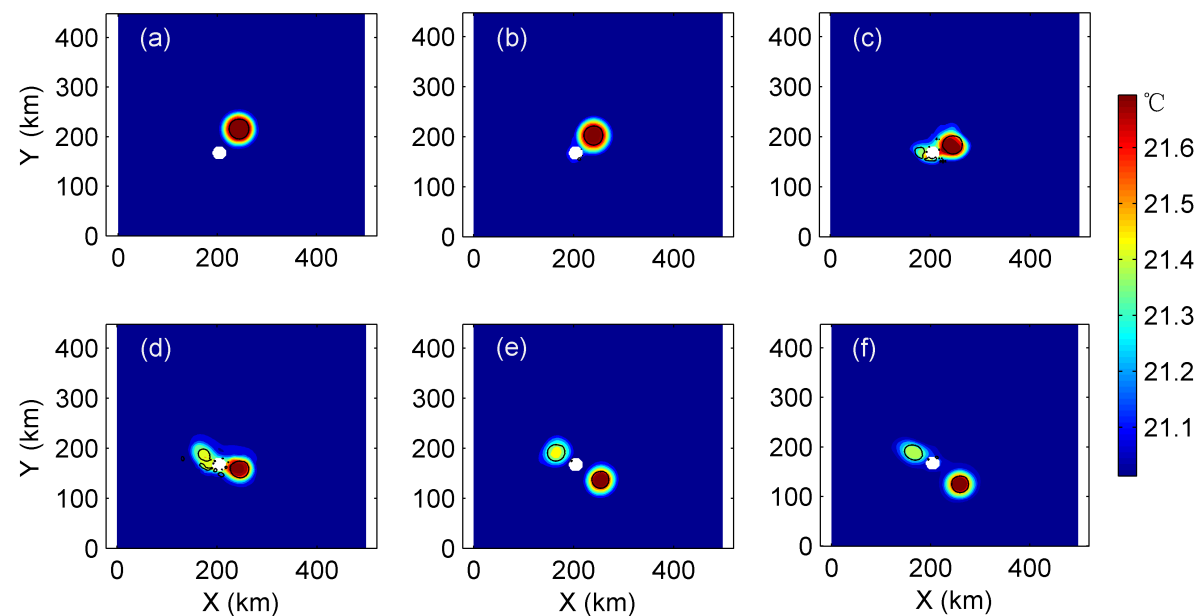

Figure 4. The process of eddy-splitting induced by the interaction with an island of $20 \mathrm{~km}$ in diameter over 50 days. A time series of snapshots of temperature at $100 \mathrm{~m}$ depth is shown in colour. (a) The initial state, (b) 10 days, (c) 20 days, (d) 30 days, (e) 40 days and (f) 50 days. The black solid lines are the $O-W$ parameter with a value of $-0.2 \sigma_{\mathrm{w}}$.

tics. However, the cold eddy moves to a higher latitude in the northern hemisphere while the warm eddy moves to a lower latitude because of their different spin directions.

When an isolated eddy propagates in open oceans with a flat bottom, while the $\beta$ effect drifts the eddy westwards (Shi and Nof, 1994), nonlinearity provides the meridional component of movement (e.g. Chang et al., 2012; Hyun and Hogan, 2008). From the results of the model, the warm eddy generally moves in the southwest direction in the northern hemisphere, which agrees with previous studies. The trajectory of the cold eddy is mirror symmetric with the warm eddy (Fig. 2). Both eddies' propagation speed is about $2.4 \mathrm{~km} \mathrm{day}^{-1}$, which is smaller than the value in previous numerical investigations which used mesoscale eddies with a $100 \mathrm{~km}$ horizontal scale (Wei and Wang, 2009; Sutyrin et al., 2003). The eddy propagation speed associated with the eddy size increases with increasing eddy size but will be limited by the maximum Rossby wave phase speed.

\subsection{Eddy-splitting}

The influence of an island on the eddy deformation is explored in this study. According to the eddy-splitting at Dongsha island in the SCS (Chang et al., 2012), we set an island on the path of the warm eddy based on the first case we have examined. The diameter of the island is $20 \mathrm{~km}$. At the beginning of the model integration, the eddy is not influenced by the island because the distance between the eddy and the island is not sufficiently close. As the eddy moves towards the island along its trajectory, the eddy eventually interacts with the island.

It is evident from Fig. 4 when the eddy collides with the island, that there is another weak warm eddy formed on the other side of the island. The two eddies have similar diam- eters but the secondary eddy is weaker than the main one, which can be seen from sea surface height (SSH), temperature, potential vorticity anomaly (PVA), and $O-W$ field (Fig. 5). In eddy-splitting, the temperature and PVA can be seen as a tracer. From the temperature distribution we can find that the water of the secondary eddy is derived from the original eddy, so we believe that the secondary eddy comes from eddy-splitting rather than being formed independently. After the eddy-splitting, the two eddies move away from the island along their own trajectories as independent eddies. When a cold eddy encounters an island with $20 \mathrm{~km}$ diameter in its trajectory, the eddy split in the same way with the warm eddy (Fig. 6). Therefore, only the warm eddies are used to study the influence of an island/seamount on the eddysplitting.

As mentioned previously, when an eddy collides with an island, the eddy can split into two eddies with similar rotation characters. Here we examine the evolution of the eddysplitting process. Figure 7 shows the temperature field evolution of an anticyclonic eddy colliding with an island with a diameter of $20 \mathrm{~km}$. The eddy is initially located at $40 \mathrm{~km}$ northeast of the island. Then the eddy moves towards the island at $0.023 \mathrm{~m} \mathrm{~s}^{-1}$. At $t=20$ days, the eddy gradually collides with the island and the isolated anticyclone is cut by the island. The fluid at the edge leaks to the right (looking offshore) due to the presence of the solid boundary of the island. The eddy loses mass along the edge of the island, creating a jet moving away from the eddy.

As the inertia and $\beta$ effect push the eddy continually closer to the island, more and more warm water leaks to form a jet with higher velocity. From $t=26$ days, because of the curved edge of the island, the jet moves forward off the boundary. The jet trajectory curves to the right side under the influence of the earth's rotation. Until $t=32$ days, the water leaking as 

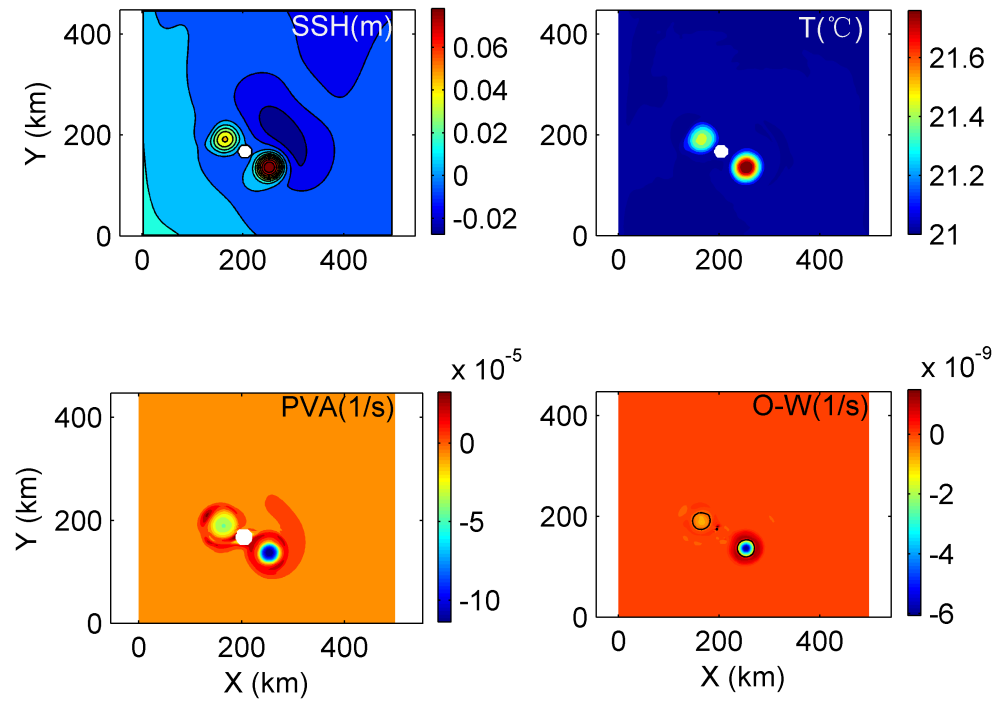

Figure 5. The warm eddy splits into two eddies during the interaction with an island of $20 \mathrm{~km}$ in diameter on day 50 (the results shown are at $100 \mathrm{~m}$ depth).
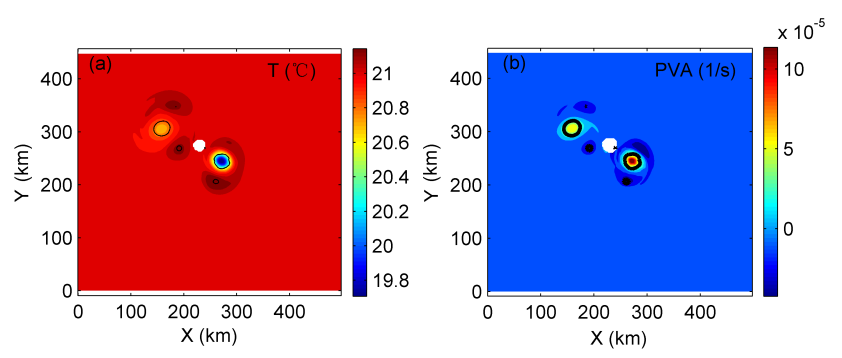

Figure 6. The cold eddy splits into two eddies during the interaction with an island of $20 \mathrm{~km}$ in diameter on day 50 (the temperature (a) and potential vorticity anomaly, PVA, (b) shown are at $100 \mathrm{~m}$ depth). The black solid lines are the $O-W$ parameter with a value of $-0.2 \sigma_{\mathrm{w}}$.

a jet becomes weaker as the eddy stops squeezing onto the island. At the same time, the warm water trapped by the jet gathers at the downstream and merges into the newly formed anticyclone eddy.

The radius of the newly formed anticyclone is about $25 \mathrm{~km}$, which is similar with the parent eddy, but its strength is weaker. Under the boundary effect, both eddies move away from the island. As a result, the parent anticyclonic eddy splits into two anticyclonic eddies during the interaction with the island.

For a better understanding of the mechanism of the eddysplitting process, the PVA field is analysed, which is shown in Fig. 8. The eddy is composed by two parts: one is the inner part with negative PVA and the other is the outer annulus with positive PVA. As shown in the figure, from $t=22$ days, at the start stage, the water leaked out is outer annulus water with positive PVA and forms the original jet. When the jet flows off the boundary from $t=24$ days, there is an anticyclonic eddy formed due to the flow shear effect at the corner, which is the separation point of the jet and the boundary. At $t=32$ days, as the eddy pushes closer to the island, more warm water with lower vorticity flows into the newly formed anticyclone under the influence of the Coriolis force. When the warm water merges into the anticyclonic eddy, the new anticyclone matures gradually similar to the parent eddy by geostrophic adjustment and moves off the island. As shown in Fig. 8, the newly formed anticyclonic eddy is weaker than its parent eddy counterpart.

The position of the newly formed anticyclone is controlled by the separation point of the jet and the island boundary and therefore is influenced by the boundary curvature, which is a function of the island scale. As the island scale increases, the azimuthal angle (clockwise is positive) of the new anticyclonic eddy to the parent eddy decreases. The relationship between the positions of the eddies and the island will be discussed in Sect. 4.3 .

When the eddy encounters an obstacle, the trajectories and speed are usually drastically altered. The results show that the speed of the eddy decreases significantly when the eddy interacts with the island. Shi and Nof (1994) pointed out that the image effect and the rocket effect (caused by the jet) usually dominate when colliding with a solid obstacle, and the effect would change the original movement trend combined with the boundary effect. At the same time, the generation of a weak cyclonic eddy during the interaction of warm eddies with an island/seamount adds a significant effect to the eddy propagation.

Actually, an anticyclonic eddy can never split on its own. Nof (1990) demonstrated this by applying the conservation law of integrated angular momentum (IAM). As a result, 

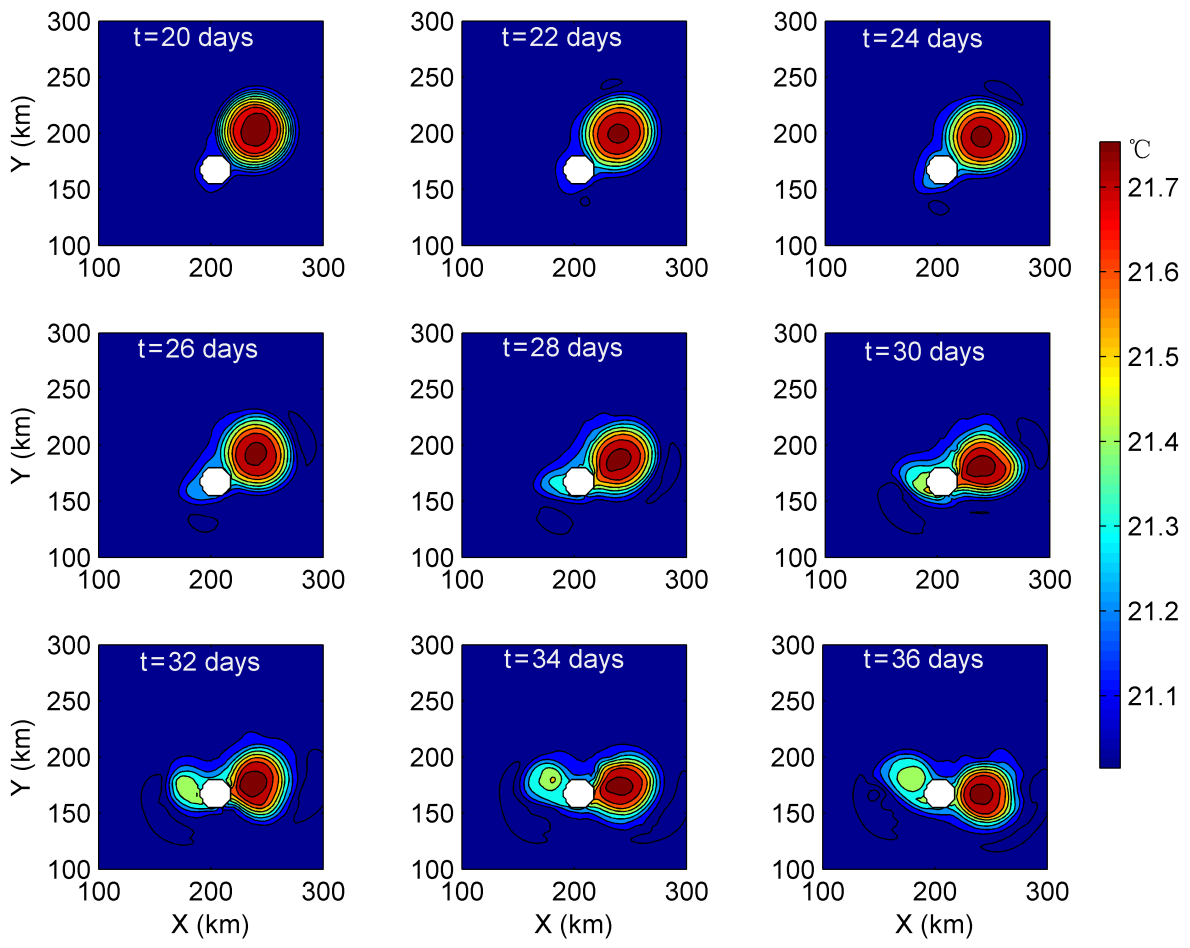

Figure 7. The temporal evolution of the eddy in the interaction with an island of $20 \mathrm{~km}$ in diameter. The colours represent the temperature at $100 \mathrm{~m}$ depth and the solid lines are temperature contours.
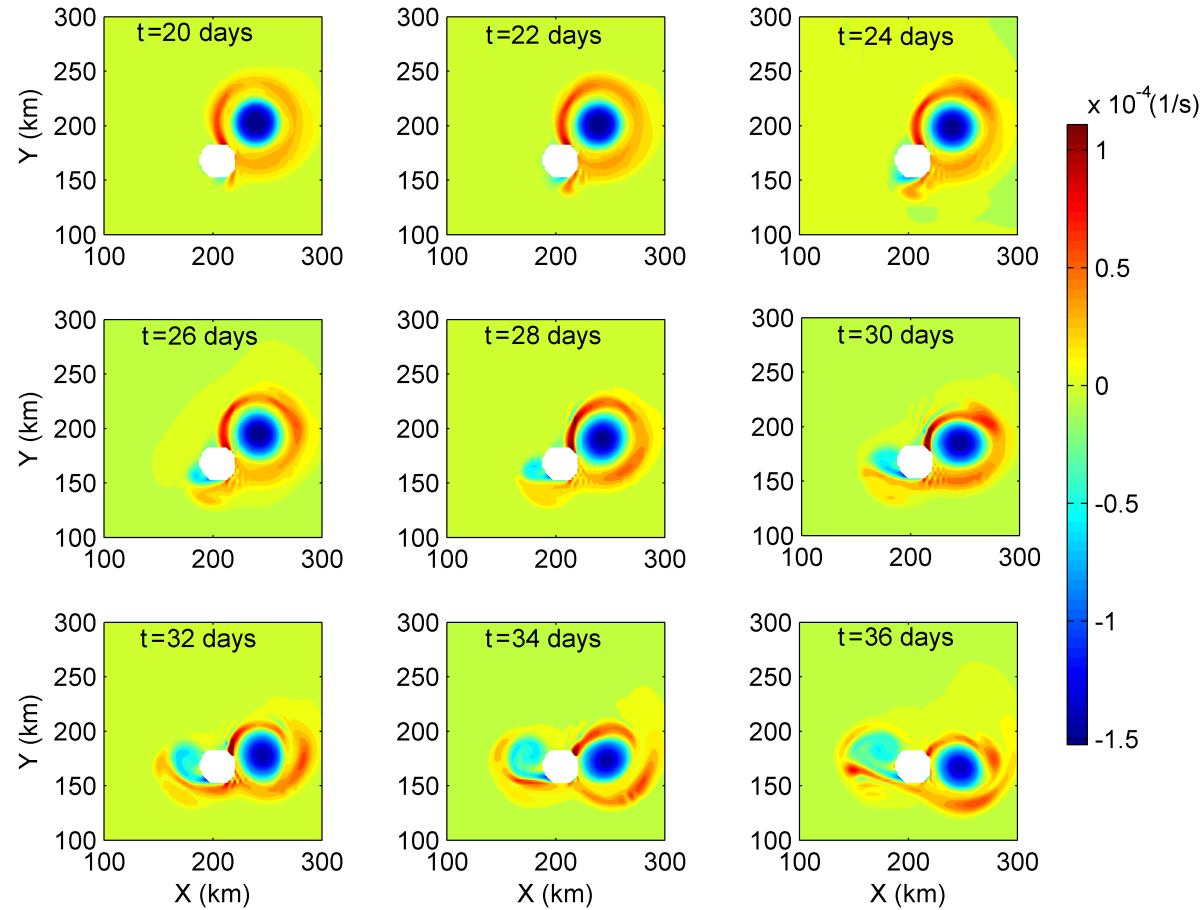

Figure 8. The temporal evolution of the eddy in the interaction with an island of $20 \mathrm{~km}$ in diameter. The colours represent the potential vorticity anomaly (PVA) at $100 \mathrm{~m}$ depth. 

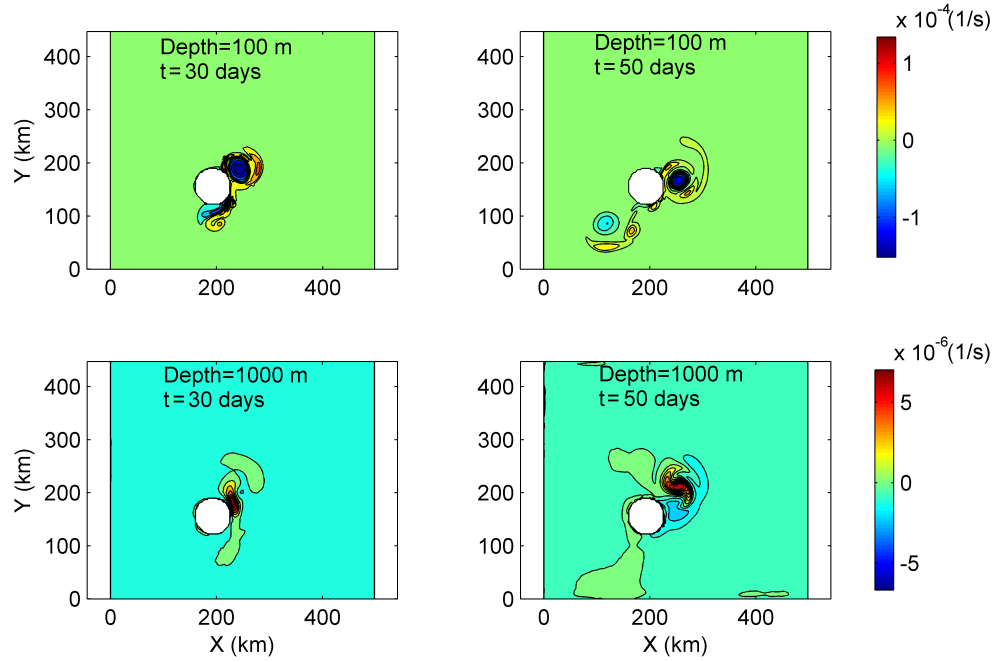

Figure 9. The potential vorticity anomaly (PVA) distributions of the interaction between the warm eddy (anticyclonic eddy) and the island of $60 \mathrm{~km}$ in diameter at $100 \mathrm{~m}$ (upper panels) and $1000 \mathrm{~m}$ (lower panels) at day 30 and 50 . The colours represent the PVA and the solid lines being the PVA contours.

when a warm eddy splits, the IAM has to increase as the newly formed eddies move away from their original centre. When a warm eddy is forced by the solid boundary of an island or the lower layer of a seamount, there has to be a transfer of IAM from the surrounding fluid to the core region of the eddy (Drijfhout, 2003). In order to show the change of IAM before and after the eddy interacts with the island, the PVA at the surface layer (depth $=100 \mathrm{~m}$ ) and deep layer $($ depth $=1000 \mathrm{~m})$ at $t=30$ days and $t=50$ days are shown in Fig. 9. Compared with the PVA field at $t=30$ days, the maximum upper anticyclonic PVA decreases at $t=50$ days because of the splitting while maximum lower cyclonic PVA increases.

\subsection{The effect of island sizes on eddy-splitting}

Observational data, including satellite images and in situ measurements, indicate that when an eddy collides with a continental slope or a small island there is no eddy-splitting, only changes to its trajectory (Jacob et al., 2002; Nan et al., 2011; Wei and Wang, 2009). In order to find out the parameter ranges of eddy-splitting, we use a series of islands with different diameters at the same location in the model. Before that, interactions of different sized islands and eddies were investigated. Take, for example, the eddies with $90 \mathrm{~km}\left(E_{d d y_{90}}\right)$ and $60 \mathrm{~km}\left(E_{1 d y}\right)_{60}$ in diameter, the eddy-splitting pattern of Eddy 90 interacting with an island of $120 \mathrm{~km}$ diameter is similar to that of Eddy 60 interacting with an island of $90 \mathrm{~km}$ (Fig. 10). Although the islands and eddies are all different in size in comparison, they have approximately the same ratio of the island radius to the eddy radius in each experiment.
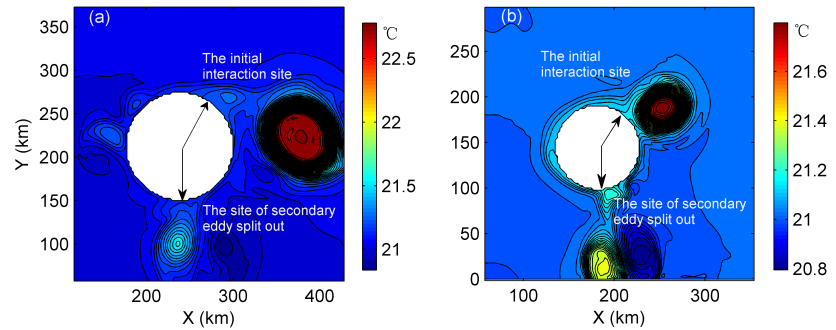

Figure 10. Comparison of the interactions between different sized islands and eddies (a) the island diameter is $120 \mathrm{~km}$ and the eddy diameter is $90 \mathrm{~km}$; (b) the island diameter is $90 \mathrm{~km}$ and the eddy diameter is $60 \mathrm{~km}$. The colours represent the temperature at $100 \mathrm{~m}$ depth and the black arrows indicate the initial eddy-island interaction site and the site of secondary eddy split-off.

We, therefore, define two dimensionless parameters $R$ and $S$ to represent the size and submergence depth of an obstacle, namely,

$R=\frac{R_{\mathrm{ob}}}{R_{\mathrm{ed}}}$,
$S=\frac{D_{\mathrm{sb}}}{D_{\mathrm{ed}}}$,

where $R_{\mathrm{ob}}$ is the radius of an obstacle; $R_{\mathrm{ed}}$ is the radius of an eddy; $D_{\mathrm{sb}}$ is the seamount submergence depth and $D_{\mathrm{ed}}$ is the vertical extent of an eddy.

The eddy collides with the islands in 20 days and interacts with them as we have described previously. Figure 11 shows when the island is small enough, namely $R<1 / 4$, the eddy does not split. Instead, the eddy will move through the obstacle, although the eddy structure deforms during the interaction process, and then recovers back after the interaction. 

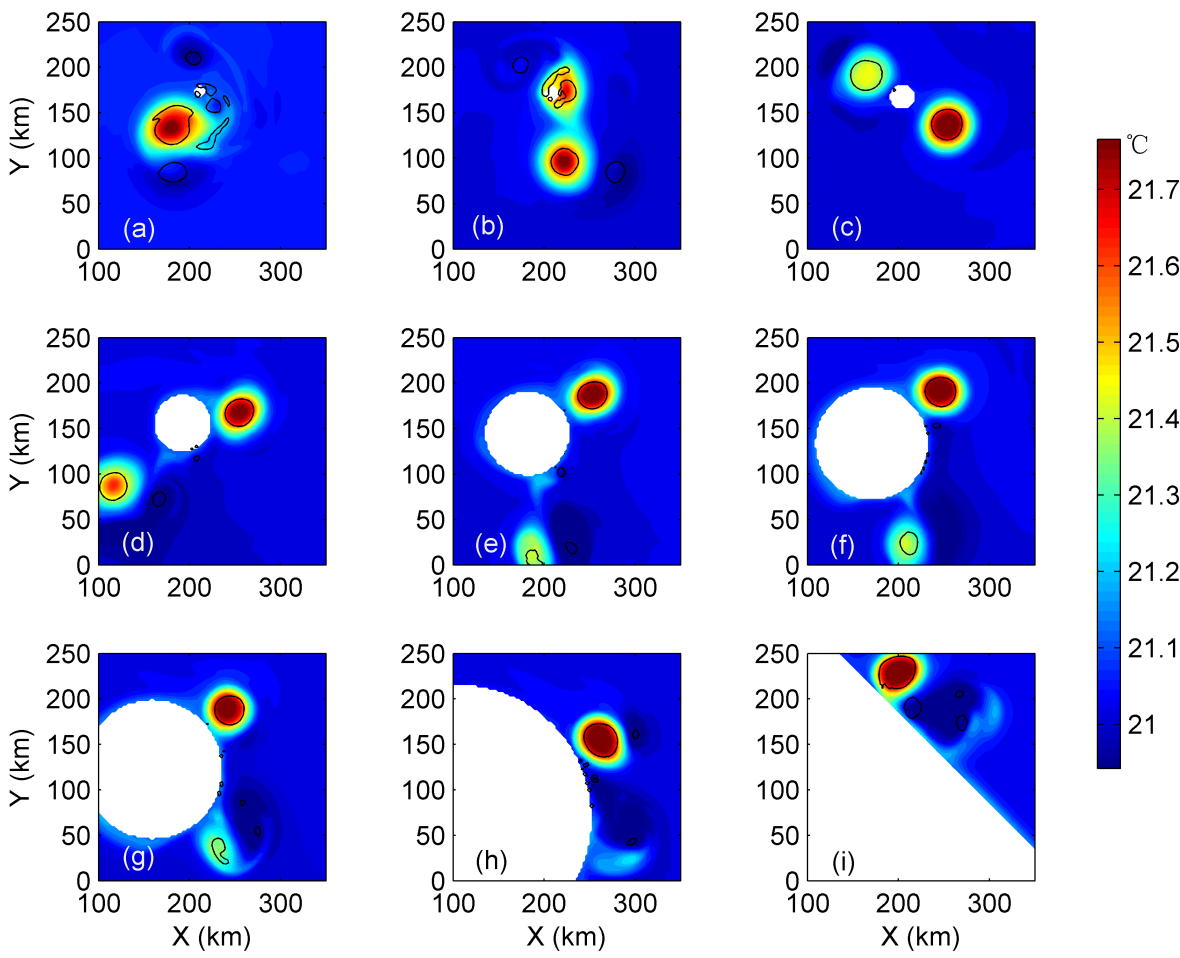

Figure 11. The results of the eddy-island interaction after 50 days for islands with different diameters (a) $10 \mathrm{~km},(\mathbf{b}) 15 \mathrm{~km},(\mathbf{c}) 25 \mathrm{~km}$, (d) $60 \mathrm{~km}$, (e) $90 \mathrm{~km}$, (f) $120 \mathrm{~km}$, (g) $150 \mathrm{~km}$, (h) $300 \mathrm{~km}$ and (i) infinite. The colours represent temperature at $100 \mathrm{~m}$ depth and the black solid lines are the $O-W$ parameter with a value of $-0.2 \sigma_{\mathrm{w}}$.

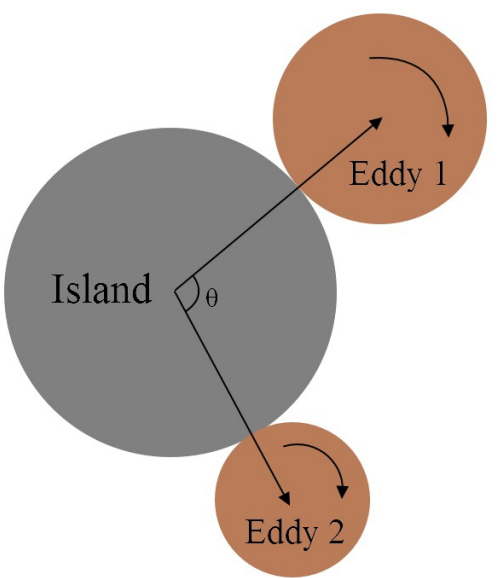

Figure 12. Sketch illustrating the position relationship of the two split eddies. When the eddy (eddy 1 ) encounters the island, the secondary eddy (eddy 2) splits-off at angle $\theta$ during the splitting.

As the island diameter increases, the "passing through" eddy gradually turns to splitting as a result of the eddy-island interaction. The eddy-splitting happens in the parameter range of $1 / 4<R<2$. As the island diameter increases to $R>2$, a filament splits-off from the eddy. This phenomenon is not considered as eddy-splitting in this study. In the last example, when the eddy collides with a solid wall (which can be seen

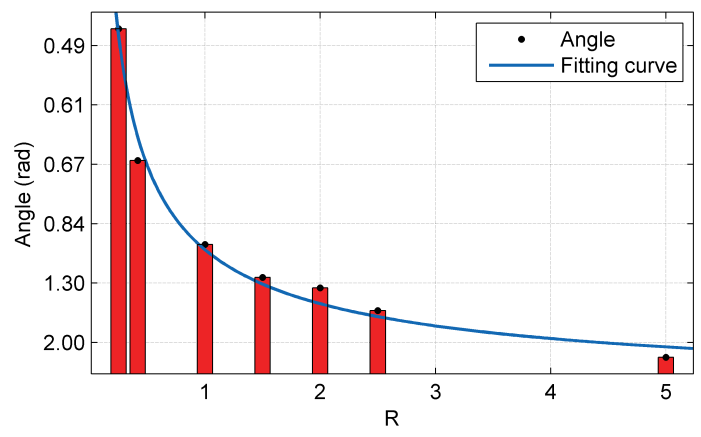

Figure 13. Distribution of relative angle (rad) with island size $(R)$. The blue line is the fitting curve.

as an island with an infinite diameter), the eddy propagates to the higher latitude along the boundary, which agrees with previous studies (Wei and Wang, 2009).

From the eddy-splitting processes with different sizes of islands, we can find that the locations of the secondary eddy split-off are related to the island size. Figure 12 shows the position relationship of the two eddies and the island. The angle $(\theta)$ between the secondary eddy and the position of collisional origin varies with the different island sizes $(R)$. The distribution of the angle $(\theta)$ and the island size $(R)$ are shown in Fig. 13. The fitting curve demonstrates that the em- 

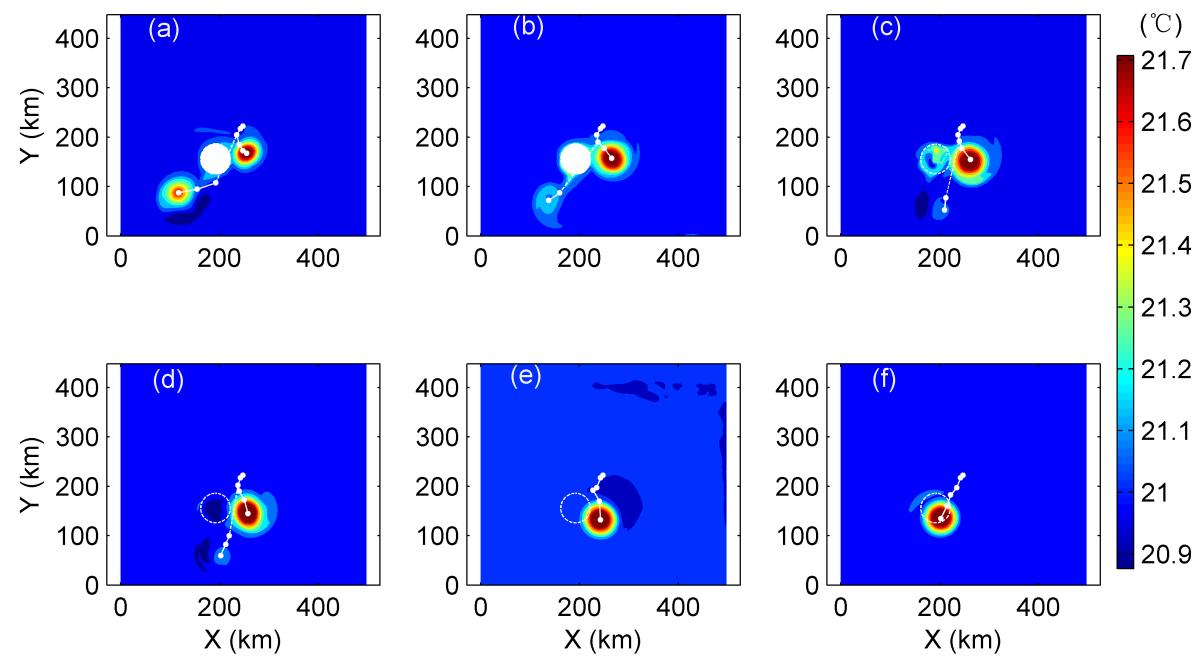

Figure 14. Eddy evolution in the case of the interaction with a seamount of $60 \mathrm{~km}$ in diameter at $100 \mathrm{~m}$ depth for different submergence depths (a) $10 \mathrm{~m}$, (b) $50 \mathrm{~m}$, (c) $100 \mathrm{~m}$, (d) $200 \mathrm{~m}$, (e) $500 \mathrm{~m}$ and (f) $1000 \mathrm{~m}$. The temperature is shown in colours and the trajectory of the eddy centre is shown by white dotted lines.

pirical relation between the angle and the island size can be written by

$\theta \sim f(R)=2.6 R^{-0.663}$

where $f(R)$ is the angle (rad) between the two split eddies related to the island.

\subsection{Effect of a seamount on eddy-splitting}

In natural oceans, islands are just part of the topography and there are more seamounts which are submerged under the sea surface. The effect of seamounts on ocean dynamics is different from that of islands. The submergence depth and the size of a seamount are key factors in the eddy-splitting. During the interaction between an eddy and a seamount, the lower part of the eddy is affected directly by the solid seamount while the upper part is not, then the vertical structure of the eddy is deformed significantly. As a result, its trajectory and splitting process is different from that of the interaction between an eddy and an island.

\subsubsection{The effect of the seamount submergence depth}

Here we investigate the effect of seamount submergence depth on eddy-splitting. The experiments are set up based on the cases of $R=1 / 4,1$ and 2, which have typical eddy splitting. Model results for the seamount with a diameter of $60 \mathrm{~km}$ are presented in Fig. 14. When the submergence depth is $50 \mathrm{~m}$, which is shallow, the interaction process between the eddy and the seamount is similar to that of the interaction between an eddy and an island. With the increase in depth, eddy-splitting becomes weaker and weaker. When the seamount submergence depth is $100 \mathrm{~m}$, the upper layer of the eddy moves under the inertia effect while the lower part is hindered by the seamount; this leads to a change of in the eddy vertical structure and the upper water of the eddy is stranded by the seamount. At the same time, the filament, which sheds from the eddy, is closer to the main body of the eddy compared with the case of an island.

When the seamount submergence depth is $200 \mathrm{~m}$, the effect of the seamount on the eddy structure has weakened greatly compared with the seamount submergence depth of $100 \mathrm{~m}$. Apart from the filament shedding, there is no significant change in the main structure of the eddy. The result also shows that the seamount with $S=2 / 5$ cannot induce the eddy-splitting. When the submergence depth is $500 \mathrm{~m}$ $(S \approx 1)$, the seamount only affects the bottom of the eddy. The eddy trajectory changes under this circumstance. Figure $14 \mathrm{e}$ shows that the eddy will bypass the obstacle from the left side under the effect of the secondary circulation in the deep layer. When the seamount submergence depth is $1000 \mathrm{~m}$ $(S>1)$, the existence of the seamount does not impact the eddy motion, and the warm eddy moves towards the southwest, which is similar to the case of a flat bottom.

From the results of the numerical experiments, we find that eddy-splitting happens roughly in the range of $S<1 / 5$ when the seamount diameter is $60 \mathrm{~km}$. Similarly, when the seamount is $10 \mathrm{~km}$ in diameter, the eddy-splitting occurs at $S<1 / 10$. Actually, the range of eddy-splitting in the seamount cases is related to the seamount horizontal size as discussed in the next section.

\subsubsection{The effect of the seamount size}

When an eddy collides with a seamount, the effect of the seamount on eddy-splitting is weaker than that of an island. The effect of the seamount on eddy-splitting is not only determined by the submergence depth but also influenced by 

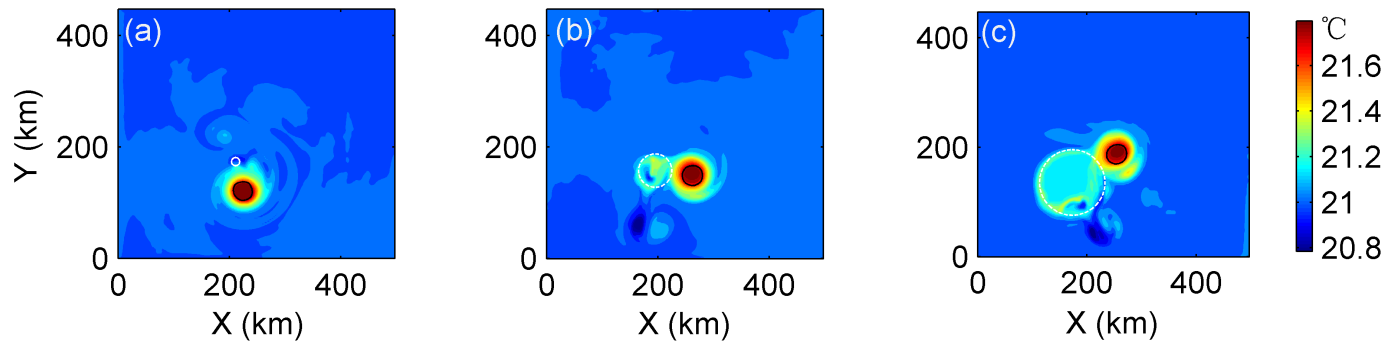

Figure 15. Eddy evolution at $100 \mathrm{~m}$ depth during the interaction with different size seamounts with a submergence depth of $100 \mathrm{~m}$. (a) $15 \mathrm{~km}$, (b) $60 \mathrm{~km}$ and (c) $120 \mathrm{~km}$. The temperature is shown in colours and the white dashed lines are the positions of the seamount; the black solid lines are the $O-W$ parameter with a value of $-0.2 \sigma_{\mathrm{w}}$.

the seamount horizontal scale. Here we test three different sized seamounts with the same submergence depth (Fig. 15). During the interaction between the eddy and the seamount with $15 \mathrm{~km}$ diameter, the eddy does not split, and when the seamount diameter is $60 \mathrm{~km}$ a small eddy is split-off while the main eddy deforms. For the seamount with $120 \mathrm{~km}$ diameter, intense deformation occurs in the eddy without splitting.

For a seamount, the eddy-splitting happens in a narrower band of horizontal scale compared with an island. As the seamount submergence depth increases, the influence of the seamount on eddy deformation decreases. Therefore the band of seamount horizontal scale for which the eddy-splitting occurs becomes narrower and narrower as the submergence depth increases.

Concerning eddy evolution in the ocean, we have explored the effect of topography such as islands and seamounts on eddy-splitting. According to the results we obtained, the dependence of eddy-splitting on the parameters $\mathrm{R}$ and $\mathrm{S}$ is summarized in Fig. 16. This diagram illustrates the main settings of the experiments and the red area is where eddy-splitting occurs.

\section{Summary and discussion}

Motivated by the eddy-splitting near Dongsha island in the SCS, we have explored the eddy's trajectory and effect of topography on an idealized eddy evolution. The MITgcm is used in the study of the effect of topography on eddy evolution including eddy trajectory and its structure, particularly the eddy-splitting when the eddy collides with an island/seamount. The topography used in the numerical experiments includes a flat bottom, islands with different diameters and seamounts with different submergence depths. Eddies colliding with the topography all have the same initial structure. The simulation results of PVA, $\mathrm{SSH}$, temperature and the $O-W$ parameter are analysed.

The model eddies (both warm and cold) move at a speed of $2.4 \mathrm{~km} \mathrm{day}^{-1}$ in open oceans under the planetary $\beta$ and nonlinear effects. The warm (cold) eddy moves southwestward (northwestward). The eddy's speed and trajectory are

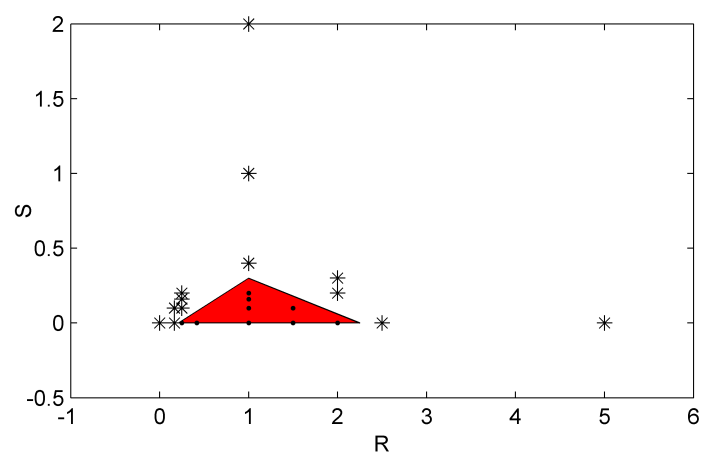

Figure 16. The range of $R$ and $S$ parameters studied and the dependence of qualitative features of the collision between eddies and obstacles. The star symbols represent no eddy splitting in the collision, and the solid dots represent eddy splitting. The red area is the range of eddy splitting.

influenced by topography. Generally speaking, the effect of topography starts when the eddy is some distance away from the island. The island leads to the eddy's trajectory changing and slows down the movement of the eddy. Because of the inertia of the eddy movement, eddies interact with obstacles by collision. The dependence of eddy behaviours on the horizontal scale and submergence depth of an obstacle can be summarized using two dimensionless parameters $R$ and $S$. We have shown the qualitative range of eddy-splitting using the results of numerical model experiments. During the eddy-splitting, the location of a secondary eddy detached from the main eddy is related to the size of the island or the seamount. Results of the model experiments show that the relationship between the angle of the two eddy directions $f(R)$ and the dimensionless parameter $R$ can be written as $f(R)=2.6 R^{-0.663}$.

Because observational data of eddy-splitting in oceans is scarce, we need more comprehensive measurement data in combination with numerical models to explore the dynamic mechanisms of eddy-splitting further. In addition to the dimensionless parameters $R$ and $S$, there are other physical effects and control parameters in eddy-splitting such as the strength of an eddy which, depends on the stratification 
(Thiem et al., 2006), and the movement speed of the eddy. In this paper, a single eddy interacting with an island or seamount was studied. However, there may be another scenario such as a sequence of eddies hitting an island. The result of the first eddy interacting with the island may be different from that of the eddy behind. In our study, the island is placed in the middle of the trajectory of the eddy. The results can be much more complicated when eddies hit more to one side of the island. In short, the eddy-topography interaction is a systematic and complex problem. In order to better understand the issue, many involved factors need to be explored. Meanwhile, an investigation using more realistic model settings, such as real topography, density stratification and forcing of the northern SCS is in progress.

Data availability. All of the data and the model can be obtained by contacting the authors.

Competing interests. The authors declare that they have no conflict of interest.

Acknowledgements. The authors would like to express their sincere gratitude to the insightful comments from J. Huthnance of NOC (UK). The very constructive comments from the editor (Eric J. M. Delhez) and referees, in particular, Y. Lu (Bedford Institute of Oceanography, Fisheries and Oceans Canada), J. Berntsen (University of Bergen) and an anonymous referee have greatly helped to improve the manuscript. This work was supported by the National Key Basic Research Program of China (program 973, grant 2014CB745001), the Environmental Protection Special Funds for Public Welfare (201309006), the Shenzhen Special Funds for Future Industry Development (201411201645511650) and S. Chen is supported by the China Postdoctoral Science Foundation (2016M591159).

Edited by: Eric J. M. Delhez

Reviewed by: Jarle Berntsen, Youyu Lu, and one anonymous referee

\section{References}

Adcroft, A., Dutkiewicz, S., Ferreira, D., Heimbach, P., Jahn, O., and Maze, G.: MITgem User Manual, 1-451, http://mitgcm.org/public/r2_manual/sav_docs_20110109_1554/ online_documents/manual.html (last access: 2 October 2017), 2011.

Cenedese, C.: Laboratory experiments on mesoscale vortices colliding with a seamount, J. Geophys. Res.-Oceans, 107, 6-1-6-14, https://doi.org/10.1029/2000JC000599, 2002.

Chang, Y.-C., Chen, G.-Y., Tseng, R.-S., and Chu, P. C.: Effect of Cylindrically Shaped Atoll on Westward-Propagating Anticyclonic Eddy - A Case Study, IEEE Geosci. Remote Sens. Lett., 9, 43-46, https://doi.org/10.1109/lgrs.2011.2159298, 2012.
Chen, G., Hou, Y., Chu, X., and Qi, P.: Vertical structure and evolution of the Luzon Warm Eddy, Chinese J. Oceanol. Limnol., 28, 955-961, https://doi.org/10.1007/s00343-010-9040-3, 2010.

Cushman-Roisin, B., Tang, B., and Chassignet, E. P.: Westward Motion of Mesoscale Eddies, J. Phys. Oceanogr., 20, 758-768, https://doi.org/10.1175/15200485(1990)020<0758:wmome>2.0.co;2, 1990.

Dewar, W. K.: Baroclinic eddy interaction with isolated topography, J. Phys. Oceanogr., 32, 2789-2805, 2002.

Doglioli, A. M., Blanke, B., Speich, S., and Lapeyre, G.: Tracking coherent structures in a regional ocean model with wavelet analysis: Application to Cape Basin eddies, J. Geophys. Res., 22, 39-52, https://doi.org/10.1029/2006jc003952, 2007.

Dorofeyev, V. L. and Larichev, V. D.: The exchange of fluid mass between quasi-geostrophic and ageostrophic motions during the reflection of Rossby waves from a coast. I. The case of an infinite rectilinear coast, Dynam. Atmos. Oceans, 16, 305-329, 1992.

Drijfhout, S. S.: Why anticyclones can split, J. Phys. Oceanogr., 33, 1579-1591, 2003.

Dunphy, M. and Lamb, K. G.: Focusing and vertical mode scattering of the first mode internal tide by mesoscale eddy interaction, J. Geophys. Res.-Oceans, 119, 523-536, https://doi.org/10.1002/2013jc009293, 2014.

Herbette, S., Morel, Y., and Arhan, M.: Erosion of a Surface Vortex by a Seamount, J. Phys. Oceanogr., 33, 1664-1679, https://doi.org/10.1175/2382.1, 2003.

Herbette, S., Morel, Y., and Arhan, M.: Erosion of a surface vortex by a seamount on the $\beta$ plane, J. Phys. Oceanogr., 35, 20122030, 2005.

Hwang, C. and Chen, S.-A.: Circulations and eddies over the South China Sea derived from TOPEX/Poseidon altimetry, J. Geophys. Res.-Oceans, 105, 23943-23965, https://doi.org/10.1029/2000jc900092, 2000.

Hyun, K. H. and Hogan, P. J.: Topographic effects on the anticyclonic vortex evolution: A modeling study, Cont. Shelf Res., 28, 1246-1260, https://doi.org/10.1016/j.csr.2008.02.011, 2008.

Itoh, S. and Sugimoto, T.: Numerical experiments on the movement of a warm-core ring with the bottom slope of a western boundary, J. Geophys. Res., 106, 26851-26862, 2001.

Itoh, S., Shimizu, Y., Ito, S.-i., and Yasuda, I.: Evolution and decay of a warm-core ring within the western subarctic gyre of the North Pacific, as observed by profiling floats, J. Oceanogr., 67, 281-293, https://doi.org/10.1007/s10872-011-0027-2, 2011.

Jackett, D. R. and Mcdougall, T. J.: Minimal adjustment of hydrographic profiles to achieve static stability, J. Atmos. Ocean. Tech., 12, 381-389, 1995.

Jacob, J. P., Chassignet, E. P., and Dewar, W. K.: Influence of Topography on the Propagation of Isolated Eddies, J. Phys. Oceanogr., 32, 2848-2869, https://doi.org/10.1175/15200485(2002)032<2848:iototp>2.0.co;2, 2002.

Kersalé, M., Petrenko, A. A., Doglioli, A. M., Dekeyser, I., and Nencioli, F.: Physical characteristics and dynamics of the coastal Latex09 Eddy derived from in situ data and numerical modeling, J. Geophys. Res.-Oceans, 118, 399-409, https://doi.org/10.1029/2012jc008229, 2013.

Korotaev, G. K. and Fedotov, A. B.: Dynamics of an isolated barotropic eddy on a beta-plane, J. Fluid Mech., 264, 277-301, 1994. 
Li, Q.-Y., Sun, L., and Lin, S.-F.: GEM: a dynamic tracking model for mesoscale eddies in the ocean, Ocean Sci., 12, 1249-1267, https://doi.org/10.5194/os-12-1249-2016, 2016.

Luo, Z. and Liu, C.: An investigation into the sensitivity of idealised vortex interactions to initial conditions and island topography, Geophys. Res. Lett., 33, 313-324, https://doi.org/10.1029/2005g1024543, 2006.

Nan, F., Xue, H., Xiu, P., Chai, F., Shi, M., and Guo, P.: Oceanic eddy formation and propagation southwest of Taiwan, J. Geophys. Res., 116, C12045, https://doi.org/10.1029/2011jc007386, 2011.

Nof, D.: On the $\beta$-induced movement of isolated baroclinic eddies, J. Phys. Oceanogr., 11, 1662-1672, 1981.

Nof, D.: Eddy-wall interactions, J. Mar. Res., 46, 527-555, 1988.

Nof, D.: The role of angular momentum in the splitting of isolated eddies, Tellus A, 42, 469-481, https://doi.org/10.3402/tellusa.v42i4.11891, 1990.

Oey, L. Y.: Loop Current and Deep Eddies, J. Phys. Oceanogr., 38, 1426-1449, https://doi.org/10.1175/2007jpo3818.1, 2008.

Okubo, A.: Horizontal dispersion of floatable particles in the vicinity of velocity singularities such as convergences, Deep-Sea Res. Oceanogr. Abstr., 17, 445-454, 1970.

Olson, D. B., Kourafalou, V. H., Johns, W. E., Samuels, G., and Veneziani, M.: Aegean Surface Circulation from a SatelliteTracked Drifter Array, J. Phys. Oceanogr., 37, 1898-1917, https://doi.org/10.1175/jpo3028.1, 2007.

Rennie, S. J., Pattiaratchi, C. P., and McCauley, R. D.: Eddy formation through the interaction between the Leeuwin Current, Leeuwin Undercurrent and topography, Deep-Sea Res. Pt. II, 54, 818-836, https://doi.org/10.1016/j.dsr2.2007.02.005, 2007.

Reznik, G. M. and Sutyrin, G. G.: Non-conservation of 'geostrophic mass' in the presence of a long boundary and the related Kelvin wave, J. Fluid Mech., 527, 235-264, 2005.

Shi, C. and Nof, D.: The destruction of lenses and generation of wodons, J. Phys. Oceanogr., 24, 1120-1136, 1994.

Simmons, H. L. and Nof, D.: Islands as eddy splitters, J. Mar. Res., 58, 919-956, 2000.

Simmons, H. L. and Nof, D.: The squeezing of eddies through gaps, J. Phys. Oceanogr., 32, 314-335, 2002.

Smith, D. C. and O'Brien, J.: The interaction of a two-layer isolated mesoscale eddy with bottom topography, J,. Phys. Oceanogr., 13, 1681-1697, 1983.

Stern, M. E.: On the amplification of convergences in coastal currents and the formation of "squirts", J. Marine Res., 44, 403-421, 1986.

Stern, M. E.: Horizontal Entrainment and Detrainment in LargeScale Eddies, J. Phys. Oceanogr., 17, 1688-1695, 2010.

Sutyrin, G. G. and Grimshaw, R.: The long-time interaction of an eddy with shelf topography, Ocean Model., 32, 25-35, https://doi.org/10.1016/j.ocemod.2009.08.001, 2010.
Sutyrin, G. G., Rowe, G., Rothstein, L., and Ginis, I.: Baroclinic eddy interactions with continental slopes and shelves, J. Phys. Oceanogr., 33, 283-291, 2003.

Sutyrin, G. G., Herbette, S., and Carton, X.: Deformation and splitting of baroclinic eddies encountering a tall seamount, Geophys. Astrophys. Fluid Dynam., 105, 478-505, 2011.

Thiem, Ø., Berntsen, J., and Gjevik, B.: Development of eddies in an idealised shelf slope area due to an along slope barotropic jet, Cont. Shelf Res., 26, 1481-1495, 2006.

Umatani, S. I. and Yamagata, T.: Evolution of an isolated eddy near a coast and its relevance to the "Kyucho", J. Oceanogr. Soc. Jpn., 43, 197-203, 1987.

Waite, A. M., Thompson, P. A., Pesant, S., Feng, M., Beckley, L. E., Domingues, C. M., Gaughan, D., Hanson, C. E., Holl, C. M., Koslow, T., Meuleners, M., Montoya, J. P., Moore, T., Muhling, B. A., Paterson, H., Rennie, S., Strzelecki, J., and Twomey, L.: The Leeuwin Current and its eddies: An introductory overview, Deep-Sea Res. Pt. II, 54, 789-796, https://doi.org/10.1016/j.dsr2.2006.12.008, 2007.

Wang, G. and Dewar, W. K.: Meddy Seamount Interactions: Implications for the Mediterranean Salt Tongue, J. Phys. Oceanogr., 33, 2446-2461, https://doi.org/10.1175/15200485(2003)033<2446:MIIFTM>2.0.CO;2, 2003.

Wang, G., Su, J., and Chu, P. C.: Mesoscale eddies in the South China Sea observed with altimeter data, Geophys. Res. Lett., 30, 2121, https://doi.org/10.1029/2003GL018532, 2003.

Wang, G. H., Jilan, S. U., and Li, R.: Mesoscale eddies in the South China Sea and their impact on temperature profiles, Acta Oceanol. Sin., 24, 39-45, 2005.

Wei, J. and Wang, D.-P.: A three-dimensional model study of warm core ring interaction with continental shelf and slope, Cont. Shelf Res., 29, 1635-1642, https://doi.org/10.1016/j.csr.2009.05.009, 2009.

Weiss, J.: The dynamics of enstrophy transfer in two-dimensional hydrodynamics, Physica D, 48, 273-294, 1991.

Zhang, Y., Pedlosky, J., and Flierl, G. R.: Shelf Circulation and Cross-Shelf Transport out of a Bay Driven by Eddies from an Open-Ocean Current. Part I: Interaction between a Barotropic Vortex and a Steplike Topography, J. Phys. Oceanogr., 41, 889910, https://doi.org/10.1175/2010jpo4496.1, 2011.

Zhang, Z., Zhao, W., Tian, J., and Liang, X.: A mesoscale eddy pair southwest of Taiwan and its influence on deep circulation, J. Geophys. Res.-Oceans, 118, 6479-6494, https://doi.org/10.1002/2013jc008994, 2013.

Zhang, Z., Wang, W., and Qiu, B.: Oceanic mass transport by mesoscale eddies, Science, 345, 322-324, https://doi.org/10.1126/science.1252418, 2014 